\begin{tabular}{|c|c|c|}
\hline & $\begin{array}{c}\text { International Journal of Current Research } \\
\text { and Academic Review }\end{array}$ & $\begin{array}{c}\text { IATERAATIONAL IOURAGL } \\
\text { OF CURRERT RESEARCH } \\
\text { ARD ACADEMIO REVIEW } \\
\text { ISSL- 2347. } 3215 \\
\text { VOL.4 ISSUE-8 } \\
\text { AuguSt-2016 }\end{array}$ \\
\hline $\begin{array}{l}\text { EXCELLENT } \\
\text { PUBLISHERS }\end{array}$ & $\begin{array}{c}\text { ISSN: 2347-3215 Volume } 4 \text { Number } 8 \text { (August-2016) pp. 111-121 } \\
\text { Journal home page: } \underline{\text { http://www.ijcrar.com }} \\
\text { doi: } \underline{\text { http://dx.doi.org/10.20546/ijcrar.2016.408.010 }}\end{array}$ & \\
\hline
\end{tabular}

\title{
Prevalence Comparison of Constipation and Fecal Incontinence Associated between Attention Deficit Hyperactivity Disorder in Children referred to a Psychiatric Clinic and Healthy Children in 2014-2015
}

\author{
Forough Riahi ${ }^{1}$, Ashraf Tashakori ${ }^{2}$ and Maryam Memar ${ }^{3 *}$ \\ ${ }^{1}$ Assistant Professor, Department of Psychiatry, Golestan hospital, Ahvaz Jundishapur \\ University of Medical Sciences, Ahvaz, Iran \\ ${ }^{2}$ Associate Professor, Department of Psychiatry, Golestan hospital, Ahvaz Jundishapur \\ University of Medical Sciences, Ahvaz, Iran \\ ${ }^{3}$ Student of General Medicine, Department of Medicine, Student Research Committee, Ahvaz \\ Jundishapur University of Medical Sciences, Ahvaz, Iran
}

\section{KEYWORDS}

ADHD, constipation, fecal incontinency, abdominal pain, nausea, vomiting.

\section{A B S T R A C T}

Attention deficit hyperactivity disorder, one of the most common behavioral disorders in childhood. Attention deficit hyperactivity disorder through three primary symptoms including inattention, hyperactivity and impulsivity becomes clear that each child may cause for other disorders. One of these disorders is functional constipation. Fecal incontinence also occurs with functional chronic constipation. The objective of this study was to evaluate the incidence of dification disorders and gastrointestinal symptoms in people with attention deficit hyperactivity disorder. This study was a cross - sectional study in 2014- 2015. The control group of 100 children 4-16 years old at the level of several schools in the city of Ahvaz was randomly selected. And for the people with questionnaires Parent Rating Scale-Revised Conner's (CRSP) for ADHD disorder rejected. The target group of 100 children who were referred to child psychiatry and by tow Child and Adolescent psychiatrists, according to DMS-IV criteria for ADHD has been diagnosed recently and their rankings determined by questionnaire CRSP; Were taken History of constipation and fecal incontinence and symptoms gastrointestinal, such as nausea, vomiting and abdominal pain and demographic questionnaire completed by the researcher for both groups The data were analyzed using SPSS version 22 and chi-square test and P. Value significant amount of less than 0.05 was determined. ADHD was not increasing the risk of dification disorders including constipation and fecal incontinence and gastrointestinal symptoms including nausea, vomiting and abdominal pain. Statistical analysis of each of the variables include constipation :( $\% 35.1$ of children with ADHDvs. $23.3 \%$ children without ADHD; $\mathrm{P}=.06$ ) and fecal incontinence $3.1 \%$ of children with ADHDvs. $2.9 \%$ of children without ADHD; P $=0.94)$. Abdominal pain (13.4\% of children with ADHDvs. $6.8 \%$ of children without ADHD; $\mathrm{P}=0.12$ ). Nausea (3.1\% of children with ADHDvs. $2.9 \%$ of children without ADHD; $\mathrm{P}=0.94)$ and vomiting (1\% of children with ADHDvs. $1.9 \%$ of children without ADHD; $\mathrm{P}=0.59$ ). No clear didn't exist association between the prevalence of functional constipation and fecal incontinence and gastrointestinal symptoms including abdominal pain, nausea and vomiting with risk of ADHD. 


\section{Introduction}

Attention deficit hyperactivity disorder, one of the most common behavioral disorders in childhood and through three primary symptoms including inattention, hyperactivity and impulsivity disorders known each other for the child (1). One of these disorders is functional constipation in children due to neglect it ignores the need for disposal and disposal into delays. This leads to stool retention and constipation (2). Fecal incontinence in children with Attention deficit hyperactivity disorder and chronic constipation can be seen in the most severe form. As the children due to complete loss of natural landmarks go to the toilet, Disposal as flooding and leaking into their underwear(3). Other side effects include constipation, chronic abdominal pain, anus and rectum, severe attacks of abdominal pain before bowel movements caused and urinary symptoms including urinary incontinence $(29 \%)$ during the day or night $(34 \%)$, urinary tract infection girls $(33 \%)$ and boys (3\%) can be seen (4).

Attention deficit hyperactivity disorder is a major issue mental health and its importance is due to its high prevalence. Overall, $3.7 \%$ of children in the population and $50 \%$ of children with psychiatric disorders to suffer from it $(5,6)$. In a study to assess the prevalence of ADHD in Ahvaz city of Iran on the male preschoolers was to show that the frequency of this disorder with parents' censer's questionnaire was $4.51 \%$ (7).

Constipation is a common gastrointestinal problem in children and adults in the community and found many that would impose a huge cost to society. The prevalence of constipation in children is estimated to be $3-8 \%$. The main complaining at $3-5 \%$ outpatient physicians and pediatricians and $25 \%$ of the patient of pediatric gastroenterologists are included (8).

One of the reasons for treatment failure in people with gastric disorders is behavioral issues such as counter-seeking behaviors and Attention deficit hyperactivity disorder (9, 10, 11). The study Mckeown and et al., in 2013 increased prevalence of constipation and fecal incontinence in children with Attention deficit hyperactivity disorder indicated(3) and we also study the prevalence of constipation and fecal incontinence and gastrointestinal disorders such as nausea, vomiting and abdominal pain in children with attention deficit hyperactivity disorder to examine these patients in order to treat your digestive problems better, more precise behavior of individual psychotherapy and Group one approach is used.

\section{Methods}

This study is a cross-sectional epidemiological study in 2014-2015 and 200 children 4-16 years old in the city of Ahvaz. The sample size of the study using Mckeown et al., (3). And by using Cochran formula with $\mathrm{d}=.04$ and $\mathrm{P}=0.041$ and the percentage of $95 \%$ was determined. The control group of 100 children 4-16 years old at the level of several schools in the city of Ahvaz was randomly selected. And for the people with questionnaires Parent Rating Scale-Revised Conner's (CRSP) for ADHD disorder rejected also The target group of 100 children who were referred to child psychiatry and by tow Child and Adolescent psychiatrists, according to DMSIV criteria for ADHD has been diagnosed recently and their rankings determined by questionnaire CRSP, were selected and After explaining the purpose of the study and obtaining informed consent in two groups, a questionnaire consisting of three 
parts: In the first part demographic data including age, gender, first child of family, city of residence, ethnicity, education level of parents, age, and occupation-parent family population and family economic status, history of addiction, psychiatric disorders and physical illness in family subjects, as well as physical illness and use of drugs in children and In the second part the history of bowel problems include constipation and fecal incontinence, gastrointestinal symptoms such as nausea, vomiting and abdominal pain, are included, of the participants were asked. Noting that the six criteria for functional constipation have been shown to have at least two criteria exists in children as young as 4 years (criteria Rome III) (12).

The third section, ADHD questionnaire that much abbreviated version Conners rating scale for parent is provided by keithconner in 1973 and includes ten items to assess hyperactivity and inattention. Scoring questions using a four-grade scale (not at all, somewhat, high and very high) was carried out with the full score was 30 points higher than 15 is considered positive for ADHD, score 15 to 20 as mild, 21 to 25 as moderate and 26 to 30 is classified as severe (12). This questionnaire of more than $90 \%$ sensitivity and specificity of $77 \%$ to $98 \%$ correct classification rate (Correct Classification Rate)\% 84 to\% 96 (13) This measure tools as the most common symptoms of attention deficit disorder Hyperactivity used (12) and in Iran is normalized (14) in the absence of satisfaction to participate in the study, did not interfere in the process of therapy and in case of other major psychiatric disorders and mental retardation and severe physical disease based on clinical assessment and constipation-inducing drugs, patients were excluded from the study. The study Ethical Committee of Ahvaz University School of
Medicine was approved with a number IR.AJUMS.REC.1394.614.

After collecting the required data using SPSS version 22 to analyze the data collected data is analyzed by chi-square test was used to compare the prevalence of constipation and fecal incontinence and gastrointestinal symptoms, including nausea, vomiting and abdominal pain in both ADHD and children were used. According to statistical considerations P.Value meaningful amount for the project was set less than 0.05 .

\section{Results and Discussion}

In this study, 100 ADHD and 100 healthy children, whit aged 4-16 years in terms of bowel disorders including constipation and fecal incontinence and gastrointestinal symptoms including nausea, vomiting and abdominal pain were compared using chisquare.

The prevalence of constipation in patients with ADHD was $35.1 \%$ and healthy children was $23.3 \%$ and no was difference between the two groups the statistically significant, there was no risk of functional constipation $(\mathrm{P}=0.06)$.

By comparing the fecal incontinence in people with ADHD, 3.1\% have fecal incontinence and $2.9 \%$ among healthy children with fecal incontinence that weren't significant differences between the two groups, there was no risk of fecal incontinence $(\mathrm{P}=0.94)$.

The Prevalence of abdominal pain in patients with ADHD and healthy children showed that is $13.4 \%$ of patients with ADHD and were $6.8 \%$ healthy children $(\mathrm{P}=0.12)$ a significant relationship between 
the prevalence of abdominal pain in patients with ADHD and healthy controls not found.

In a survey of nausea among people with ADHD and healthy children showed that people with ADHD $3.1 \%$ and healthy children were $2.9 \%$ that had nausea and a statistically significant difference between the two groups wasn't seen $(\mathrm{P}=0.94)$.

In this study, the check of prevalence of vomiting in people with ADHD and healthy children showed that people with ADHD 1\% and healthy children were $1.9 \%$ that had vomiting And a statistically significant difference between the two groups wasn't $\operatorname{seen}(\mathrm{P}=0.59)$.

In this study by comparing the criteria for functional constipation individually showed that two criteria of functional constipation including hard stools and associated whit pain with $\mathrm{P}=0.00$ and large diameter stool whit $\mathrm{P}=0.03$ has found a significant relationship between the two groups. In Table 2, compare the prevalence of functional constipation in ADHD and healthy children.

In this study, demographic data on people with ADHD Studied that include age, gender, and first child of family, city of residence, ethnicity, level of education parent and people, age and occupation of the parents, family and economic situation of the population, their history of addiction, psychiatric disorders and physical illness in the family subjects, as well as a history of physical illness and consumption of drugs in children showed that age, maternal age population and family history of psychiatric disorders have the highest correlation in ADHD people. Also first child of family and gender as variables in other studies in people ADHD, studied, and a statistically significant association in this study; have been examined.

According to a survey ADHD disorder in age groups 8-4 years, 9-12 years and 16-13 years respectively disorder ADHD, 42\%, $60 \%$ and $47 \%$, and the prevalence in the age group 9-12 years with $\mathrm{P}=0.00$ had the highest prevalence.

According to this study, the prevalence of ADHD in boys $55 \%$ and $37 \%$ of girls say prevalence of the disorder among boys was higher by $\mathrm{P}=0.01$. Also in this study considering that $54.8 \%$ of ADHD birth of the first child of the family and other children constituted $40 \%$ and was $\mathrm{P}=0.03$ Reflects the increase ADHD who were first child of family. In the relationship between maternal age and the prevalence of ADHD showed that $55.6 \%$ of women aged $30-40$ and $34.3 \%$ of women aged $41-50$ years and due to the $\mathrm{P}=0.00$, ADHD disorder in children of mothers who fourth decade of life have been more than mothers aged 4050 years. The prevalence of ADHD in the people who lived in an extended family, $30 \%$ and $56.4 \%$ of the population Low population with regard to the $\mathrm{P}=0.00$ showed the prevalence of ADHD in large families has declined.

The relationship between the prevalence of psychiatric disorders in families with a history ADHD, $68.8 \%$ of people in your family have a history of psychiatric disorders and was $46.7 \%$ of patients without a psychiatric disorders and according to the $\mathrm{P}=0.05$, the increased prevalence of ADHD in association with a the patient had a history of psychiatric disorders in relatives. In the Table 3 is shown the prevalence demographic data inADHD.

Because the most significant relationship in our study of ADHD, in relation to age, 
maternal age, family history of psychiatric disorders and population of family, the correlation mentioned in other statistical analysis, the prevalence of functional constipation in patients with ADHD, paid to other possible factors in the creation of functional constipation in patients with ADHD, and to discover and with consideration of these factors, make better decisions on individuals in order to provide treatment to this group.

The results of the statistical analysis according to the above table shows that in the age group 9-12 years, $26.5 \%$ of people with ADHD, has been constipation and $47.6 \%$ of people don't have been constipation. Due to the P-value $=0.06$ was more than 0.05 suggests that in people with ADHD in this age, there isn't an increased prevalence of constipation.

ADHD persons who were mothers aged 3040 years was $61.8 \%$ of them have constipation, while $84.1 \%$ of them don't have constipation. according to the $\mathrm{P}$ value $=0.01$, which is less than 0.05 , indicating in people with ADHD, there is a significant relationship between maternal age and the risk of constipation and the prevalence of constipation in people with ADHD that mothers with lower age is less.

Also in this analysis due to the populated family of people with ADHD, 20.6\% of them have constipation and $17.5 \%$ with ADHD has not constipation and $\mathrm{P}$-value = 0.7 and more than 0.05. So the crowd population of family and individuals having constipation in the people with ADHD there is no significant relationship.

The study in patients with ADHD that have a history of psychiatric disorder in family, $2.9 \%$ of them have constipation and $15.9 \%$ of patients don't have constipation were given $p$-value $=0.9$ was more than 0.05 then between familial history of psychiatric in people with ADHD and coalition constipation there is no significant relation.

In Table 4 constipation correlation with demographic data has been measured in people with ADHD.

The results of this study showed that among people with ADHD, $35.1 \%$ and $23.3 \%$ among healthy children with constipation that were not a significant correlation between the incidence of constipation and ADHD. However, due to the $\mathrm{P}=0.06$ can say that perhaps Will be significant this relationship with increasing sample size and prevalence of constipation in patients with ADHD increase.

However, in this study by comparing the criteria for functional constipation individually in those two criteria, including hard stools associated with the pain and stool large diameter, has found a significant relationship Although bowel disorders, functional constipation criteria completely in these patients has not filled. McKeown and et al., in 2013 on 750,000 children 4-12 years old, showed the prevalence of constipation in people with ADHDhigher (3). In other study Attention deficit hyperactivity disorder prevalence in children with functional constipation in patients of digestive Abuzar hospitals in Ahwaz at 2012 also showed Attention deficit hyperactivity disorder in children with functional constipation, which is $13.5 \%$ be suggestive of ADHD as one of the causes of functional constipation in children (15).

In this study, Schlander and et al., on 630 patients ADHD known with age less than 20 years of age, showed there are a range of disorders, that gastrointestinal diseases and metabolic disorders as well as part them in 
Int.J.Curr.Res.Aca.Rev.2016; 4(8): 111-121

patients with $\mathrm{ADHD}(16)$. Other studies also show ADHD has high comorbidity with other disorders (17).

Studies in 2010 and 2011 in relation to the dietary patterns in people with ADHD showed low intake of vitamin c, leading to lower levels of zinc and copper in their diet and this can also be as an influential factor on constipation and fecal incontinence in ADHDchildren $(18,19)$. Also, in our study the prevalence of fecal incontinence in patients with ADHD and healthy children showed doesn'texist a correlation between the prevalence of fecal incontinence in people with ADHD. While McKeown and et al., studied the relationship is a significant and the prevalence of fecal incontinence was higher in subjects with ADHD (3). And we can say this relationship is not significant in our study may be due to the sample size is low.

There is a neurobiological disorder that described in other studies behavior problems like ADHD was demonstrated in This disorder can change the relationship between the nervous system and bowel system, delay in bowel movements and changes in bowel distension perception of can explain to constipation and bowel disorder as the study Beaker and cooperation in this field showed that in people with constipation and fecal incontinence and bowel dysfunction it's related to between perceptual processing in the nervous system and intestinal system And this study may suggest an association between behavioral problems and disorders of the bowel (20).

In a study case report in a child who has been treated with sertraline drug and a significant improvement in terms of fecal incontinence; Stronger evidence to explain the enteric nervous system and environment changes and showed possible associations to describe the relationship between ADHD and fecal incontinence (21).

Also known association ADHD and urinary incontinence stronger evidence provided to explain the neurobiological cause (22).

In addition ADHD and bowel disorders may be structured as a nervous disorder associated with aging are reduced (23).

In another study in 2008 by Van Everdingen-Faasen and et al., in relation to psychosocial problems impact on treatment outcome was fecal incontinence Showed that of 150 children with fecal incontinence who had not recovered a year with regular treatments There was at least one problem in 95\% of Psycho-Social and psychotherapy at the same time, $69 \%$ of people over 12 month successful, But treatment in children with ADHD, in children with problems associated with parents and mentally retarded children was not successful(24).

In our study, healthy children and ADHD, gastrointestinal symptoms such as nausea, vomiting and abdominal pain have also been determined that correlation was not found between the two groups in these gastrointestinal symptoms.

In a study Almog et al., in 2010, 62 children with ADHD and 57 healthy children compare by in terms of frequency of gastrointestinal symptoms such as abdominal pain, diarrhea, constipation, food allergies and showed a higher frequency of food allergies in children with ADHD, and in general there was no obvious correlation between gastrointestinal symptoms and ADHD (25).

But in a study in 1999 by Helen and colleagues examined the relationship between physical symptoms with anxiety 
disorders, depression, conduct disorder and oppositional defiant disorder and ADHD children and adults with biopsy was performed, showed on the girls the prevalence of abdominal pain, headache and musculoskeletal pain associated with anxiety disorders, but boys with ADHD and oppositional defiant disorder are abdominal pain and musculoskeletal pain associated with depression in both sexes (26).

On the other hand benninga and colleagues who study the relation between bowel disorders and behavioral programs for children with anorectal function parameters and associated colon transit time was indicated in 215 Patients' age group 5-14 with bowel disorders, 135 people with constipation, 56 patients with fecal incontinence and 24 with recurrent abdominal pain were children with bowel disorders, behavioral problems than the control group, but there were no behavioral problems in children with abdominal pain(27).

In another study by sally and colleagues in 2007 on the prevalence of psychiatric symptoms in children and adults with the frequent vomiting syndrome, Showed in children with anxiety disorders, but this syndrome in adults with panic disorder after the accident (PTSD) and somatization disorders associated (28). But no study has been done on the prevalence of disorder in ADHD.

In our study also examined demographic information, gender, first child of the family, age, psychiatric disorders and maternal age and population family has significant relationship with $\mathrm{ADHD}$ So that ADHD disorder is more common in men, and this finding in all studies have had similar results (29).
Our study more prevalent in the age group 9-12 years in ADHD but kochakzadesalemi and etal study of healthy and colleagues as well as in the study Moradi and etal highest incidence in the age of 5 years $(30,31)$.

In another study in our country at the age of 3-4 years, the rate of these disorders is more; but in another study there was no significant relationship between age and ADHD (32, 33).

In Review Prevalence of ADHD and rank of birth, our results showed that the frequency of the first child of the family is more common in ADHD and this result was similar in McKeown and colleagues, the study Abdollahian and etal and kochakzadesalemi and etal in $\operatorname{rasht}(3,30,33)$.

ADHD in children of mothers who were the living quarters was more than mothers with the age group 40-50 years. And in study of kochakzadesalemi and etal also showed that between attention deficit disorder and hyperactivity and age were significantly correlated parents. So that the mean age of fathers and mothers was lower in ADHD children (30). In our study, the same frequency with the age of the fathers was not significant. By comparing the population of family in the incidence of this disorder, showed the prevalence of ADHD in large families (more than four) decreased.

While the study Abdollahian and etal and kochakzadesalemi and etal don't found a significant relationship between the population family and $\operatorname{ADHD}(30,31)$.

Considering that our study of age, maternal age, family history of psychiatric disorders and populations family have most statistically significant relationship with the occurrence of ADHD. In another statistical analysis studied the correlation between 
Int.J.Curr.Res.Aca.Rev.2016; 4(8): 111-121

variables in ADHD with functional constipation to discover other possible factors in the creation functional constipation in patients with ADHD, and by taking these factors, make better decisions on individuals in the treatment group. Given that the similar studies haven't been done to investigate the correlation.

In this analysis considering that ADHD was the highest prevalence in the age group 9-12 but the prevalence of constipation in these patients were not more than other patients in other age groups.
Statistical analysis also compared to the family crowd and having constipation in patients with ADHD. Statistically significant was not found relationship and with the population growing family, not increase the risk of constipation.

In this study, the relationship between the incidences of constipation in patients with ADHD has mothers 30-40 years and mothers with ages 40-50 years were measured. The results showed that in patients with ADHD, there is a significant relationship between mother age and the risk of constipation. It can be concluded in ADHD with constipation, mothers are older.

Table.1 Comparison of dification disorders and gastrointestinal symptoms in

ADHD children and healthy children

\begin{tabular}{|c|c|c|c|}
\hline Group Disorder & ADHD & $\begin{array}{c}\text { Healthy } \\
\text { children }\end{array}$ & $\mathbf{P}$ \\
\hline constipation & $35.1 \%$ & $23.3 \%$ & 0.06 \\
\hline fecal incontinency & $3.1 \%$ & $2.9 \%$ & 0.94 \\
\hline abdominal pain & $13.4 \%$ & $\% 68$ & 0.12 \\
\hline nausea & $3.1 \%$ & $2.9 \%$ & 0.94 \\
\hline vomiting & $1 \%$ & $1.9 \%$ & 0.59 \\
\hline
\end{tabular}

Table.2 Comparison of the prevalence of functional constipation in ADHD and other people

\begin{tabular}{|c|c|c|c|}
\hline $\begin{array}{c}\text { Criteria of functional } \\
\text { constipation }\end{array}$ & ADHD & $\begin{array}{c}\text { Healthy } \\
\text { children }\end{array}$ & $\mathbf{p}$ \\
\hline $\begin{array}{c}\text { Dification time }<\mathbf{2} \text { in } \\
\text { week }\end{array}$ & $20.6 \%$ & $14.6 \%$ & 0.26 \\
\hline Special posture & $21.6 \%$ & $20.4 \%$ & 0.82 \\
\hline Large diametr stool & $39.2 \%$ & $25.2 \%$ & 0.03 \\
\hline $\begin{array}{c}\text { Large diametr fecal in } \\
\text { rectum }\end{array}$ & $6.2 \%$ & $7.8 \%$ & 0.78 \\
\hline Hard diffication & $21.6 \%$ & $7.8 \%$ & 0.00 \\
\hline
\end{tabular}


Int.J.Curr.Res.Aca.Rev.2016; 4(8): 111-121

Table.3 ADHD individual distribution based on demographic characteristic

\begin{tabular}{|c|c|c|c|c|}
\hline \multicolumn{2}{|c|}{ Variable } & numeric & Percent & P \\
\hline \multirow{4}{*}{ Age } & $4-8$ & 50 & $42 \%$ & \multirow{2}{*}{0.00} \\
\cline { 2 - 4 } & $9-12$ & 39 & $60 \%$ & \\
\cline { 2 - 4 } & $13-16$ & 8 & $47 \%$ & \\
\hline \multirow{2}{*}{ Gender } & Male & 70 & $55 \%$ & \multirow{2}{*}{0.01} \\
\cline { 2 - 4 } & Female & 27 & $37 \%$ & \\
\hline \multirow{2}{*}{ Birth } & first child & 63 & $54.8 \%$ & \multirow{2}{*}{0.03} \\
\cline { 2 - 4 } & Other children & 34 & $40 \%$ & \\
\hline \multirow{2}{*}{$\begin{array}{c}\text { Faternal age } \\
\text { population }\end{array}$} & $30-40$ & 74 & $55.6 \%$ & \multirow{2}{*}{0.00} \\
\cline { 2 - 4 } $\begin{array}{c}\text { psychiatric } \\
\text { disorders }\end{array}$ & O1-50 & 33 & $34.3 \%$ & \\
\cline { 2 - 4 } & Oow population & 79 & $30 \%$ & \multirow{2}{*}{0.00} \\
\cline { 2 - 4 } & Yes & 11 & $68 \%$ & \\
\hline \multirow{2}{*}{} & No & 86 & $46.7 \%$ & \\
\hline
\end{tabular}

Table.4 Demographic data correlation constipation with ADHD

\begin{tabular}{|c|c|c|c|}
\hline & $\begin{array}{c}\text { ADHD- } \\
\text { constipation }\end{array}$ & $\begin{array}{c}\text { ADHD-no } \\
\text { constipation }\end{array}$ & P \\
\hline Age(9-12) & $26.5 \%$ & $47.6 \%$ & 0.06 \\
\hline Maternal age(30-40) & $61.8 \%$ & $84.1 \%$ & 0.01 \\
\hline Over crowded & $\% 20.6$ & $17.5 \%$ & 0.7 \\
\hline $\begin{array}{c}\text { With psychiatric } \\
\text { disorders }\end{array}$ & $2.9 \%$ & $15.9 \%$ & 0.9 \\
\hline
\end{tabular}

So overall, we can conclude our study age, family population history of psychiatric disorders in ADHD with constipation does not increase of risk of constipation. In the event that the mother's age it's related the prevalence of constipation in people with ADHD and those older mothers have a higher incidence of constipation.

Which may cause a lack of awareness of on the regulation of $\mathrm{ADHD}$ diet and learn the correct pattern dification to children by mothers was associated and leading to increased prevalence of constipation in these individuals. Of course, proving this, more and more studies are needed .

\section{Acknowledgments}

In this way all children and parents who helped us in conducting this study, would be appreciated. This study was approved and funded by the research department of Ahvaz University has been implemented as a means of Deputy Management and employees thank our respected in this field. The authors also thank the Golestan Hospital Clinical Research Development Unit of Ahvaz Jundishapur University of Medical Sciences especially Ms. Hannaneh Davoodzadeh.

\section{References}

Abdollahian E, Shakeri M, Vosough E. The prevalence of attention deficit and hyperactivity disorder in preschool-age children in Mashhad, north-east of Iran. Medical Journal of Mashhad University of Medical Science. 2004; 47(84):275280. 
Almog M, Gabis LV, Shefer S, Bujanover Y. Gastrointestinal symptoms in pediatric patients with attention deficit and hyperactivity disorders. Harefuah. 2010 Jan; 149(1):33-6, 62.

Bakely RA. A Clinical Work book,Attention Deficit Hyperactivity Disorder,2 ed.New York,Guilford,1998.

Baker SS, Liptak GS, Colletti RB, Croffie $\mathrm{JM}$, Dilorenzo $\mathrm{C}$, Ector $\mathrm{W}$, et al.,.Constipation in infant \&children:evaluation\& treatment.

Amedical position statement of the North American society for pediatric gastroenterology \& nutrition.J. Pediatrgastroenterol nutr.1999; 29(5):612-26.

Benninga MA, Voskuijlwp, Akkerhuis GW\&etal. Colonic transit times and behaviour profiles in children with defecation disorders. arch dis child.2004; 89(1):13-16.

Bongers ME, van WijkMP,Reitsma JB \&etal. Long- term prognosis for childhood constipation: clinical outcomes in adulthood constipation. Pediatrics. 2010; 126(1).

Duel BP, Steinberg-Epstin R, Hill M, A survey of voiding dysfunction in children with attention deficithyperactivity disorder. J Uril. 2003; $170(4$ pt 2):1521-1523, discussion 1523-1524.

Habrani P, Bahdani F.Gender differences in comorbid disorders with attentiondeficit/hyperactivity disorder (ADHD).Horizon Med Sci 2006;11(4):55_61.

Karami H, Mousavi A, Khademloo M, Soleimani F. Etiology of chronic constipation and related causes in children referred to Boo_AliSina Hospital in Sari between.journal of Birjand University of Medical Sciences 2010;16(4): 51- 6.

Kiddie JY, Weiss MD, Kitts DD, et al. Nutritional status of children with attention deficit hyperactivity disorder: a pilot study.int J Pediatr: 2010; 2010:767318.

Kim Y,Chang H. Correlation between attention deficit hyperactivity disorder and sugar consumption, quality of diet, and dietary behavior in school children. NutrresPract. 2011; 5(3):236- 245.

Kliegman R, Stanton B, Geme J, SchorN,BehrmanR.Nelson textbook of pediatrics.19th ed.USA: Saunders;2011.p.108-112.

kochakzadetalemi S, Namazi A, Zarkesh M, Attention deficit hyperactivity disorder in children under school age based on parental report. Holistic Nursing and Midwifery.2015; 25(74):35-44.

Linkegger HE, Costello JA, Erkanl Al. Somatic Complaints and Psychopathology in Children and Adolescents: Stomach Aches, Musculoskeletal Pains, and Headaches: journal of the American academy of child and adolescent psychiatry. 1999: 38(7): 852-860.

Loening-Baucke V. Encopresis. Curr Opin Pediatr 2002; 14:570.

Loening-Bauke V. Prevalence, symptom \& outcome of constipation in infants \& toddlers. J Pediatr. 2005; 146(3):35963.

Lourence L. Attention Deficit Hyperactivity Disorder. In: Kaplan and sadock Comprehensive text book of Psychiatry.eds: Sadock BJ Sadock VA, Ruiz P.Philladelphia Lippiaeot Williams and wilkins 2009; 3560-5.

McKeown C, Hisle-Gorman E, Eide M, Gorman GH, Nylund CM. Association of Constipation and Fecal Incontinence With Attention-Deficit/Hyperactivity Disorder. Pediatrics. 2013 Nov; 132(5):e1210.

Miele E, Simone D, Mrino A, Gereco L, Auricchio R, Novek SJ, et al.,.Functional gastrointestinal disorders in children: An Italian spectiveurvey. Pediatrics.2004;114(1):73-80.

MikkelsenEj, Sadock BJ Sadock V A, Ruiz P, Editor. Kaplan and sadock 
Comprehensive text book of Psychiatry. Philladelphia Lippiaeot Williams and wilkins 2009:3632.

Moradi A, Mohammadalizadeh S, Alai V, Fakhari A, Asadollahi M. Sign attention deficit hyperactivity disorder in preschool age children on base parents reported in kindergardens. Daneshvar journal. 2006; 12(57):47-54.

Rasquin A, DiLorenzo C, Forber D, Guiraldes ER, Hyams JS, Staiano A, Walker LS. Childhood Functional Gastrointestinal Disorder: Child Adolescent. Gastroenterology 2006;130:1527-1537.

Riahi F. Evaluation of co morbidity prevalence of hyperactivity _ attention deficit in children and teenagers referred to the psychiatric clinic of Golestan Hospital based on reported cases in 20.3. 2008 to 19.3. 2010. In6th International Congress on Child and Adolescent Psychiatry 2013 Sep 17. TabtizUniversity of medical sciences.

Rockney R. Encopresis. Developmental Behavioral Pediatrics, 3rd, Levine MD, Carey WB, Crocker AC (Eds), WB Saunders, Philadelphia 1999. p.413.

Rowland As, Lesesne CA, Abramowitz AJ.the epidemiology of attentiondificit/hyperactivity disorder (ADHD); a public health view. Mentard Dev Disabil Resrev. 2002; 8(3):162-170.

Schiander M ,Schwarz O, Trott G ,Vlapiano M, Bonaur N. Attention-dficit/ hyperactivity in Grown-ups: Administrative Data on Co-Existing Condition .Institute for Innovation and Valuation in Health care.2003.
Shabani M.Yadgari A. Assessment prevalenceattentiondeficit hyperactivity disorder in school age, Zanjan. medicalScience.2006; 13(51):42-48.

SinzingJ, Morsch D, Lehmkuhi G .Do Hyperactivity, impulsivity and inattention have an impact on the ability of facial affect recognition in children with autism and ADHD. Child Adolese Psychiatry. 200872-17:63؛

Tarbell S. Buk Li. Psychiatric Symptoms in Children and Adolescents With Cyclic Vomiting Syndrome and their Parents;The Journal of Head and Face Pain. 2008: 48(2): 259-266.

Tashakori A, Afkandeh R. Prevalence of ADHD Symptoms amonge Male Preschoolers Based on Different Informants in Ahvas City of Iran. ISRN pediatrics. 2011 Oct 25; 2011

vanDijk M, Benninga MA, Grootenhuis MA, Last BF. Prevalence and associated clinical characteristics of behavior problems in constipated children. Pediatrics 2010; 125:e309.

VanEverdingen-Faasen EQ, Gerritsen BJ, Mulder PG, Fliers EA, Groeneweg M. Psychosocial co-morbidity affects treatment outcome in children with fecal incontinence. Eur J Pediatr. 2008 Sep; 167(9):985-9. Epub. 22983377.

Zarouni $M$. Investigate the Prevalence of Attention Deficit - Hyperactivity Disorder (ADHD) in children with Functional Constipation, and symptoms associated with a range of underlying factors [dissertation].[Ahvaz]: JondiShapour University of Medical Sciences; 2012.50.

\section{How to cite this article:}

Forough Riahi, Ashraf Tashakori and Maryam Memar. 2016. Prevalence Comparison of Constipation and Fecal Incontinence Associated between Attention Deficit Hyperactivity Disorder in Children referred to a Psychiatric Clinic and Healthy Children in 2014-2015. Int.J.Curr.Res.Aca.Rev.4(8): 111-121. doi: http://dx.doi.org/10.20546/ijcrar.2016.408.010 